\title{
A rare case of chronic endometritis treated with hysteroscopy
}

\section{Neena Gupta ${ }^{1 *}$, Sachidanand Gupta ${ }^{2}$, Seema Dwivedi $^{1}$, Sangeeta Arya ${ }^{1}$, Pavika Lal ${ }^{1}$, Monica Chauhan ${ }^{1}$}

\author{
${ }^{1}$ Department of Obstetrics \& Gynaecology, GSVM Medical College, Kanpur, UP, India \\ ${ }^{2}$ Department of Anaesthesia, Rama Medical College, Kanpur, UP, India
}

Received: 14 October 2013

Accepted: 27 October 2013

\author{
*Correspondence: \\ Dr. Neena Gupta, \\ E-mail: neena.gupta2211@gmail.com
}

(C) 2013 Gupta $\mathrm{N}$ et al. This is an open-access article distributed under the terms of the Creative Commons Attribution Non-Commercial License, which permits unrestricted non-commercial use, distribution, and reproduction in any medium, provided the original work is properly cited

\begin{abstract}
We present a case of 32 year old woman complaining of menometrorrhagia with chronic pelvic pain of following second trimester abortion. Her transabdominal ultrasound revealed chronic endometritis. She was treated with dilatation and curettage, on histopathological examination diagnosis of chronic endometritis was confirmed. Her menorrhagia was revealed but chronic pelvic pain persisted for which diagnostic hysteroscopy was planned. It revealed presence of tiny bony chips which were removed in the same setting. Intrauterine retained foetal bony chips due to previous medical termination of pregnancy were identified to be the cause of menometrorrhagia with chronic pelvic pain in the present case. Our case reiterates the importance of hysteroscopy in evaluation of such patients who are not responding to conventional medical management of abnormal uterine bleeding.
\end{abstract}

Keywords: Intrauterine fetal bones, Menometrorrhagia, Chronic pelvic pain, Hysteroscopy

\section{INTRODUCTION}

Retained fetal bones in the uterine cavity are a very rare condition which may be subsequent to intra uterine death and missed abortion. Reported incidence of retained fetal bones is $0.15 \%$ among diagnosed hysteroscopy. ${ }^{1}$ Prolonged retention may cause pelvic inflammatory disease, chronic pelvic pain, abnormal uterine bleeding, offensive vaginal discharge and spontaneous elimination of bony fragments along with menses in addition to secondary infertility. ${ }^{2}$

\section{CASE REPORT}

Mrs. X age 32 yrs $\mathrm{P} 2+2$ presented in gynecology O.P.D. with chief complaints of menometrorrhagia along with chronic pelvic pain since 3 years following induced abortion of 3 months amenorrhea which was followed by dilatation and curettage. On detailed obstetric history, she had one preterm vaginal delivery and one full term caesarean section (indication -fetal distress) with one living issue followed by two induced abortions, last one 3 years back. On per speculum and per vaginal examination - no abnormality was diagnosed except that significant bleeding was present. She was advised admission. Her urine pregnancy test was done which was negative. Her complete blood count, liver renal and thyroid function tests were within normal limits except her hemoglobin which was $8.2 \mathrm{gm} \%$. Her transabdominal ultrasound revealed normal uterine size with echogenic contents in the uterine cavity. She underwent diagnostic and therapeutic dilatation and curettage and tissue was sent for histopathology which revealed chronic endometritis. She was given oral antibiotics along with hemostatic agents and low dose combined oral contraceptives. She remained asymptomatic for next 3 months but was not relieved of chronic pelvic pain. Therefore, hysteroscopy was planned which revealed tiny bone fragments which were removed at the same setting with the help of hysteroscopy grasper. Her intraoperative and 
postoperative period was uneventful and she was discharged satisfactorily.

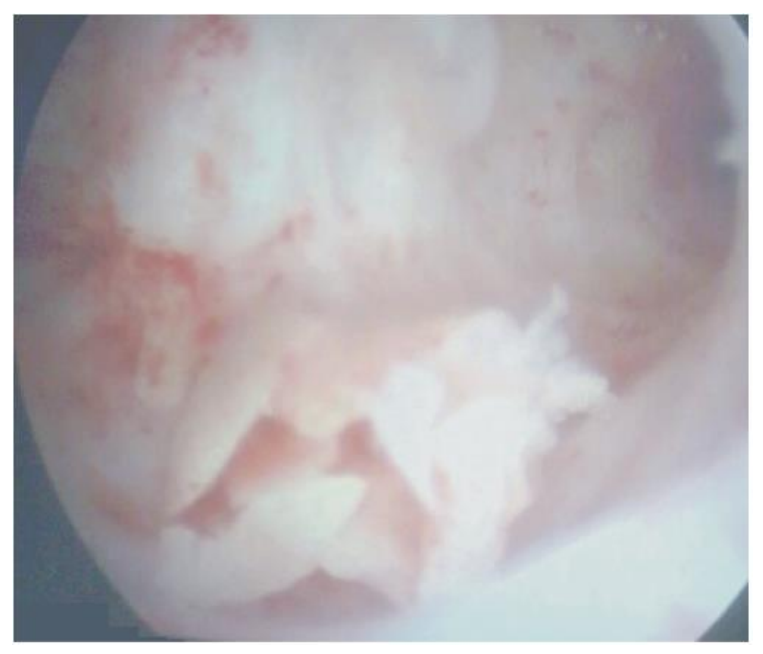

Figure 1: Hysteroscopic view of bony chips.

\section{DISCUSSION}

Retention of foetal bones in the uterus is a rare complication of abortion or following removal of a macerated foetus. Roth and Taylor hypothesized that without a previous pregnancy loss, metaplasia of mature endometrial stromal cells into bony tissue occurs in response to chronic inflammation or trauma. ${ }^{3}$ In early 1990 Melius et al found $>50$ cases in the literature with $80 \%$ occurring after pregnancy. ${ }^{4}$ The diagnosis was traditionally suspected from filling defects on hysterosalpingography, with the definitive diagnosis made on blind curettings. Therapy had generally been restricted to curettage or hysterectomy. ${ }^{5-7} \mathrm{~A}$ blind $\mathrm{D}+\mathrm{C}$ is sometimes diagnostically inaccurate and often ineffective as it may miss focal endometrial lesions. Chan described how in his case the curettings from a blind $\mathrm{D}+\mathrm{C}$ were normal before a hysteroscopy that visualized many retained fetal bone fragments. ${ }^{8}$ Verma et al reported the case of a 20-year-oldwoman with history of multiple terminations of pregnancy leading to chronic pelvic pain which got relieved after hysteroscopic removal of the intrauterine foetal bones. ${ }^{9}$ A regular myometrialendometrial interface and homogeneous endometrial structure on transvaginal sonography congruent with the phase of the menstrual cycle indicate a normal endometrium and preclude the need for diagnostic hysteroscopy. Transvaginal sonography may be used as the initial diagnostic procedure to select patients for hysteroscopy. ${ }^{10}$

With the advent of office hysteroscopy, diagnosis can be easily made on visualization of bony fragments in uterine cavity with simultaneous removal and therefore invaluable in achieving cure for these patients without resorting to aggressive surgery.

\section{CONCLUSION}

Retained fetal bones although are a very rare entity should be considered in patients with abnormal bleeding dating from pregnancy termination who are not responding to conventional treatment of AUB. The simplicity of office hysteroscopy and good postoperative prognosis justify this invaluable procedure in both establishing the diagnosis and removal of bony fragments from the uterine cavity.

\section{REFERENCES}

1. Makris N, Stefanidis K, Loutradis D, Anastasiadou K, Hatjipappas G, Antsaklis A. The incidence of retained foetal bone revealed in 2000 diagnostic hysteroscopies. J Soc Laparoendoscopic Surgeons 2006;10:76-7.

2. Chervenak FA, Amin HKo, Neuwirth RS (1982) Symptomatic intrauterine retention of fetal bones. Obstet Gynecol 59 [Suppl]:58S-61S.

3. Roth E, Taylor H (1966) Heterotopic cartilage in the uterus. Obstet Gynecol 27:838-844.

4. Melius FA, Julian TM, Nagel TC (1991) Prolonged retention of intrauterine bones Obstet GynecoI 78:919-921.

5. Radestad A, Flam F (1995) Intrauterine retention of fetal bones after abortion. Acta Obstet Gynecol Scand 74:662-664.

6. Lewis V, Khan-Dawood F, King M, Beckmann C, Dawood MY (1990) Retention of fetal bone increases menstrual prostaglandins. Obstet Gynecol 75:561-563.

7. Graham O, Cheng L, Parsons J (2000) The ultrasound diagnosis of retained fetal bones in West African patients complaining of infertility. $\mathrm{Br} \mathrm{J}$ Obstet Gynecol 107:122-124.

8. Chan N (1996) Intrauterine retention of fetal bone. Aust NZ Obstet Gynaecol 36:368-371.

9. Verma U, Chong D, Perez I, Medina C. Fetal bones retained in the uterine cavity as a rare cause of chronic pelvic pain: a case report. J Reprod Med 2004;49:853-5.

10. Shalev J, Meizner I, Bar-Hava I, Dicker D, Mashiach R, Ben-Rafael Z (2000) Predictive value of transvaginal sonography performed before routine diagnostic hysteroscopy for evaluation of infertility. Fertil Steril 73:412-417.

DOI: $10.5455 / 2320-1770.1 j \mathrm{rcog} 20131253$

Cite this article as: Gupta N, Gupta S, Dwivedi S, Arya S, Lal P, Chauhan M. A rare case of chronic endometritis treated with hysteroscopy. Int J Reprod Contracept Obstet Gynecol 2013;2:726-7. 